\title{
The effect of nutrients on pyrrolizidine alkaloids in Senecio plants and their interactions with herbivores and pathogens
}

\author{
W. H. G. Hol
}

Received: 15 January 2010/ Accepted: 14 June 2010/Published online: 26 June 2010

(C) The Author(s) 2010. This article is published with open access at Springerlink.com

\begin{abstract}
The aim of this review is to combine the knowledge of studies on effects of nutrients on pyrrolizidine alkaloids (PAs) in Senecio with those studies of effects of PAs on herbivores and pathogens in order to predict the effects that nutrients may have on herbivores and pathogens via changes in PAs. We discuss whether these predictions match with the outcome of studies where the effect of nutrients on herbivores and insects were measured. PA concentrations in S. jacobaea, S. vulgaris and S. aquaticus were mostly reduced by NPK fertilization, with genotype-specific effects occurring. Plant organs varied in their response to increased fertilization; PA concentrations in flowers remained constant, while shoot and roots were mostly negatively affected. Biomass change is probably largely responsible for the change in concentrations. Nutrients affect both the variety and the levels of PAs in the plant. The reduced PA concentrations after NPK fertilization was expected to benefit herbivores, but no or negative responses from insect herbivores were observed. Apparently other changes in the plant after fertilization are overriding the effect of PAs. Pathogens do seem to benefit from the lower PA concentrations after fertilization; they were more detrimental
\end{abstract}

W. H. G. Hol ( $\square)$

Department of Terrestrial Ecology, Netherlands Institute of Ecology (NIOO-KNAW), Boterhoeksestraat 48, 6666 GA Heteren, The Netherlands

e-mail: g.hol@nioo.knaw.nl to fertilized plants than to unfertilized control plants. Future studies should include the effect of each element of nutrients separately and in combinations in order to gain more insight in the effect of specific nutrients on PA content in Senecio plants.

Keywords Senecio - Jacobaea $\cdot$ Nitrogen · Tyria $\cdot$ Puccinia

\section{Introduction}

Secondary metabolite concentration and composition depends on the genetic constitution of the plant, but also on (a)biotic circumstances. Attack by insects can induce the plants' defence system and similarly does $\mathrm{CO}_{2}$ concentration change the plants' weapons arsenal (Kandeler et al. 1998; Leishman et al. 1999; Hartley et al. 2000). Another influential factor affecting plant quality are nutrients. The role of nutrients in secondary metabolites production and especially pyrrolizidine alkaloids (PA) in Senecio is interesting to study for several reasons. Some members of the Senecio family are invasive weeds (Radford and Cousens 2000; Hawkes et al. 2010), while others are endangered or locally extinct species (Rossi et al. 2009; Zubek et al. 2009). The problem of Senecio as invasive weeds is not only the replacement of native species, but also their toxicity to cattle (Mattocks 1986). This toxicity is due to the toxic breakdown products of PAs. PAs occur in Senecio 
species, but also in other families e.g. Boraginaceae and Leguminosae (Smith and Culvenor 1981). Also insects and micro organisms are affected by PAs (Hol and van Veen 2002; Kowalchuk et al. 2006; Macel 2010). Nutrients provide a tool to manipulate Senecio, since nutrient levels in soil determine the outcome of competition between plants. For example, Chenopodium album competes most successfully with the weedy Senecio vulgaris when potassium levels are high (Qasem and Hill 1995). In agriculture, one might want to reduce weed pressure of Senecio species by adapting nutrient supply. Nutrient-poor pastures were found to be much more invaded by the weeds Senecio jacobaea and Senecio aquaticus than nutrient-rich pastures (Suter et al. 2007; Suter and Luscher 2008). Apparently the low amount of nutrients caused gaps in the vegetation which enabled propagules to invade the pastures. The effect of nutrients on competitiveness of Senecio does depend on species; $S$. madagascariensis actually has increased competitive advantage over oats with increasing nitrogen and phosphorus levels (Sindel and Michael 1992). Although nutrient manipulation will not always work, since some Senecio species, like $S$. vulgaris, are very plastic in their response to habitats that varied in fertility (Leiss and Müller-Schärer 2001), there are other benefits of studying Senecio-nutrient interactions. Knowledge of the effects of nutrients on PA concentrations in Senecio also allows prediction of the toxicity of the vegetation for ranging cattle (Brown and Molyneux 1996). Similarly, one should be able to predict the outcome of plant-herbivore interactions under varying nutrient conditions. Plant-herbivore interactions will also affect the outcome of competition and could be an important consideration in Senecio management. In natural areas, the approach to Senecio management is bi-fold. On the one hand the focus is on reducing invasive Senecio species. Nutrient manipulation could contribute to invasive species management, unless the invasive species are able to grow under a range of nutrient conditions, such as Senecio inaequidens is able to do (Lopez-Garcia and Maillet 2005). On the other hand, the aim in natural areas can be reestablishment of rare native Senecio species. In Poland, the success of re-introducing Senecio umbrosus was found to depend on arbuscular mycorrhiza, which are essential for nutrient acquisition (Zubek et al. 2009). Besides the benefits of nutrients for manipulation of Senecio, the response of PAs to nutrient conditions may indicate the mechanism behind PA production. Unfortunately, most nutrient manipulation studies with Senecio did not measure effect on PAs. The aim of this review is to combine the knowledge of studies on effects of nutrients on PAs with those studies of effects of PAs on insects and pathogens to predict the effects that nutrients may have on herbivores and pathogens via changes in PAs. Finally, we will discuss whether these predictions match with the outcome of studies where the effect of nutrients on herbivores and insects were measured.

\section{Effects of nutrients on PAs in Senecio}

There are two contrasting predictions of the effect that nutrients should have on PA concentrations. An increase in PA concentration is predicted based on the assumption that sufficient nutrients are available and excess nitrogen could be invested in N-containing secondary metabolites such as alkaloids. Consequently, Senecio plants on fertile soils would be better protected against herbivore attack than plants growing on nutrient-poor sites (van der Meijden et al. 1984). On the other hand, decreased PA concentrations are predicted when secondary metabolites production can not keep up with the increased biomass that follows fertilization (Koricheva 1999). Larger plants then are less defended but probably have better regrowth capacity. Trade-offs between growth and defence would only be expected when the production of PAs is physiologically costly, but this is not the case (Vrieling et al. 1996). PA production takes place in the root and total PA content of the plant is closely linked to root biomass (Hol et al. 2003; Schaffner et al. 2003). Anything that changes shoot to root ratio's, is likely to affect PA levels. Since nutrients generally increase shoot biomass relative to root biomass (Poorter and Nagel 2000), a decrease in PA concentration is expected.

Relevant papers were selected via searches on the Web of Knowledge and via references in those papers. Experimental studies with nutrients addition were limited, so also papers which used natural soil from sites with different nutrient availability were included (see Table 1). Soils different in nutrients refers to natural soils that differ in nutrients, e.g. poor 
Table 1 Effect of nutrient supply on pyrrolizidine alkaloids and biomass of Senecio plants

\begin{tabular}{|c|c|c|c|c|c|}
\hline Reference & Senecio species & Fertilizer & Plant biomass ${ }^{\mathrm{a}}$ & PAs & $\begin{array}{l}\text { Plant parts } \\
\text { PA analysis }\end{array}$ \\
\hline \multicolumn{6}{|c|}{ Experiments with field soils naturally differing in a range of nutrients } \\
\hline Frischknecht et al. (2001) & vulgaris & $\mathrm{N}$ & + & - & Shoot, flowers \\
\hline Macel and Klinkhamer (2009) & jacobaea & na & - & - & Leaves \\
\hline Joosten et al. (2009) & jacobaea & na & + & $=$ & Shoot and root \\
\hline \multicolumn{6}{|c|}{ Experiments with addition of known amounts of nutrients } \\
\hline Wilcox and Crawley (1988) & jacobaea & $\mathrm{N}$ & na & $=$ & Shoot \\
\hline Vrieling and van Wijk (1994) & jacobaea & PK & na & $=$ & Shoot \\
\hline Vrieling and van Wijk (1994) & jacobaea & NK & na & $=$ & Shoot \\
\hline Vrieling et al. (1993) & jacobaea & NPK & na & - & Shoot \\
\hline Brown and Molyneux (1996) & vulgaris & NPK & + & $=$ & Flowers \\
\hline Hol et al. (2003) & jacobaea & NPK & + & - & Shoot, root \\
\hline Kirk et al. (2009) & jacobaea & NPK & na & - & Shoot, root \\
\hline Kirk et al. (2009) & aquaticus & NPK & na & $=/ \pm$ & Shoot, root \\
\hline
\end{tabular}

${ }^{\mathrm{a}}+$, nutrients increase biomass; - , nutrients decrease biomass; $n a$, not available

sandy soil vs. rich clay soil. The nutrient availability in those soils is not known, except for mineral nitrogen in one study (Frischknecht et al. 2001). Note that sites with different nutrient availability probably also differ in microbial communities and this in itself also affects PA levels in the plant (Joosten et al. 2009). The experimental studies with nutrient addition is a collection of treatments studying nutrients mixtures or single nutrients by adding one element (e.g. nitrogen; Wilcox and Crawley 1988) or by leaving one element out of the nutrient mixture (Vrieling and van Wijk 1994). The studies working with nutrient mixtures used liquid fertilizer, slow release granules or compost. Most studies report the exact quantity of nutrient added, but not the nutrients that were already available in the soil. There are no studies that manipulate just micro elements. From other alkaloid-producing species it is known that e.g. the micro-element cobalt is positively correlated with the content of the alkaloids colchicine and colchicoside in the seeds of Colchicum autumnale (Poutaraud and Girardin 2005). Therfore, future studies should include the effect of macro and microelements separately and in combination in order to gain more insight in the effect of specific nutrients on PA content in Senecio plants. The dataset contains only results for three species (S. aquaticus, $S$. jacobaea and $S$. vulgaris). Studies with more Senecio species are necessary before drawing general conclusions on the effect on nutrients on PA concentration for all Senecio species.

The majority of papers on the effects of nutrients in the three Senecio species (Table 1), including those studies using soils/sites, demonstrate no or negative effects of nutrients on PA concentrations. Negative effects of nutrients on PA concentration could result from dilution, as indeed biomass usually increased with nutrient addition. Dilution effects may be taken for granted because of the biomass increase, but in other plant species alkaloid concentration increased after nutrient supply (Höft et al. 1996). N-fertilization even increased total alkaloid concentrations 5-10 times in the leaves of holly (Palumbo et al. 2007). More information is necessary on concentrations and biomass of all plant parts to determine whether PA production in Senecio itself is affected by varying nutrient supply (Koricheva 1999). Most studies of effect of nutrient manipulation on PAs are limited to the PA concentrations in shoots and in half of those studies biomass has not been reported (Table 1). One should not assume that the shoot is representative for the whole plants, the effect that nutrients have on PAs varies between plant organs.

Optimal defence theory predicts that the most valuable parts should be protected (van Dam et al. 1996). Flowers are closely linked with fitness and in S. vulgaris do indeed contain high concentrations of PAs (Hartmann et al. 1989). Also roots of S. jacobaea 
have high PA concentrations (Hol et al. 2003), which might be expected since roots are essential for plant (re)growth. If nutrients decrease PA concentrations, less effect would be expected in the most valuable parts, i.e. flowers in the generative stage or roots in the vegetative stage. For flowers, this indeed seems to be the case. Frischknecht et al. (2001) found similar PA concentration in the flowers of $S$. vulgaris plants growing at nutrient-rich and nutrient-poor sites, while concentration in stem and leaves were different between sites. Likewise, Brown and Molyneux (1996) found no difference in PA concentration in the flowers of $S$. vulgaris. Total flower biomass did increase, so production must have increased or PAs were allocated from elsewhere. Unfortunately, no other plants parts were analysed for PAs in this study and thus it will remain unclear whether there was an increase in PA production or a re-allocation.

For the annual $S$. vulgaris it is feasible to include flowers in the analysis, but the majority of studies used S. jacobaea, which is a biannual. Most studies with $S$. jacobaea are limited to the vegetative stages, for practical reasons. For plants in the vegetative stage, the roots are essential for survival and should be well protected. However, in an experiment with plants growing on nutrient-rich and nutrient-poor soil, PA concentration was lower in the roots of $S$. jacobaea plants growing in the fertile soil while shoot concentration was not or positively affected (Joosten et al. 2009). This suggests that the plant is not giving priority to protecting roots over shoots. Kirk et al. (2009) found that nutrient addition decreased PA concentrations in both shoot and root of $S$. jacobaea, except under very wet conditions. Similarly, another study using 4 nutrient levels reported both PA concentration in shoot and roots of $S$. jacobaea to decrease with increasing nutrients (Hol et al. 2003). Apparently, PA concentrations in the flowers stay constant despite nutrient manipulation, but there is no evidence that Senecio plants preferentially allocate PAs to the roots when nutrients are causing lower PA concentrations.

The species S. jacobaea and S. vulgaris show similar results, i.e. equal or decreased PA concentrations after fertilization. For S. aquaticus there is just a single study, where an interaction was found between water supply and nutrient addition. Within species, genotypes differ in their response to nutrients. One genotype of $S$. jacobaea growing on nutrient-rich and nutrient-poor soil may have similar PA concentrations in the shoot, while another has highest concentrations on the nutrient-rich soil (Joosten et al. 2009). Interestingly, genotype-specific effects have also been found in other alkaloid-producing species, with the strongest response to nitrogen fertilization by the genotype with lowest alkaloid content (Sreevalli et al. 2004). In a large field study with ten genotypes of S. jacobaea, most genotypes showed higher PA concentration at the nutrient-poor site (Macel and Klinkhamer 2010). Interestingly, in this study Macel and Klinkhamer (2010) found lower PA concentrations in the fertile site, but also smaller $S$. jacobaea plants. Thus, effects here are not simply due to dilution, but probably also the result of competition (at the fertile site) and induction (at the nutrient-poor site). Despite the frequently reported differences between genotypes, there are also studies with S. jacobaea and S. vulgaris that found no interaction between genotype and environment for total PA concentration (Vrieling et al. 1993; Frischknecht et al. 2001).

Nutrients not only affect PA concentration but also the composition of PAs within a plant. This might be expected since nutrient addition also affects flowering (Prins et al. 1990), which in turn is associated with PA specification (Hartmann and Zimmer 1986). However, also plants in the vegetative stage showed differences between individual PAs in response to nutrients. Macel and Klinkhamer (2010) found decreasing erucifoline concentrations at nutrient-rich soil, while jacobine concentrations hardly changed in S. jacobea. Hol et al. (2003) also showed jacobine in $S$. jacobaea to be relatively unresponsive to nutrients, compared to other PAs. Joosten et al. (2009) found that PA composition in $S$. jacobaea was significantly affected by soil-type, while the effects on total PA concentration were small. In $S$. vulgaris no alkaloid pattern was found to be associated with habitats differing in fertility (Frischknecht et al. 2001). The individual PA concentrations in the flowers of $S$. vulgaris were not affected by nutrients (Brown and Molyneux 1996). Apart from a shift in PA composition, the total diversity of PAs (number of compounds) in the shoot can also be increased by nutrients, but this was found only at extreme moisture levels for S. jacobaea and hybrids (Kirk et al. 2009).

In conclusion, PA concentrations are mostly reduced by nutrients, with genotype-specific effects 
occurring. Plant organs vary in their response to nutrients; PA concentrations in flowers were indifferent to nutrients, while shoot and roots were mostly negatively affected. Biomass change is probably largely responsible for the change in concentrations, but there are other contributing factors as well. PA composition in $S$. jacobaea is also affected by nutrients, but this has not been found in S. vulgaris.

\section{Predicting the effects of nutrient manipulation in Senecio on herbivores and pathogens}

There are numerous studies on the effects of PAs on herbivores (Macel 2010) and pathogens. In general, lower concentrations of PAs should increase nutritional quality of the plant and make it more attractive as host plant to herbivores and pathogens. Generalist herbivores and pathogens are more likely to be affected than specialists, although a certain level of PAs might be required by specialists for host plant recognition or defense against parasitoids or predators. Larval performance of the cinnabar moth, a specialist on S. jacobaea, is not correlated with total PA concentration or the diversity of PAs (Macel et al. 2002). Although fungal growth can be reduced by PAs, some fungi isolated from $S$. jacobaea and S. vulgaris roots might be adapted to and even benefit from PAs (Hol and Van Veen 2002). PAs in $S$. jacobaea roots were found to be associated with different microbial rhizosphere communities (Kowalchuk et al. 2006), which suggests that PAs are selective towards bacteria.

Obviously nutrient supply to Senecio plants will affect more than just plant biomass, PA concentration and/or composition and PA allocation to the plant organs, but also can affect the concentration and composition of other primary and secondary metabolites. All of those may interact with PAs or override their effect on herbivores and pathogens. A more holistic approach of the metabolome is necessary for identification of metabolites that determine herbivory. NMR-based metabolomics were used to demonstrate that thrips resistance in Senecio hybrids was associated not only with high levels of PAs but also with higher levels of kaempferol glucoside (Leiss et al. 2009). Primary metabolites may be as effective as defense against herbivores as secondary metabolites (Berenbaum 1995). There are proteins called "pathogenesis-related proteins" that are known to act directly as defense protein against pathogens (Ryals et al. 1996). For insects nitrogen is a very important factor determining nutritional quality. Pupal weight of Tyria jacobeaea is determined by nitrogen content of the food (Soldaat and Vrieling 1992). For oviposition T. jacobaea preferred $S$. jacobaea plants with nitrogen content in the range 2.1-3.1\% dw (van der Meijden et al. 1989). Although insects are nitrogen-limited, T. jacobaea did not select $S$. jacobaea plants with maximum nitrogen concentrations (van der Meijden et al. 1989). Similar results were found in an earlier study (van der Meijden et al. 1984). The avoidance of maximum nitrogen concentration might be due to the positive relation between nitrogen and alkaloid concentration (de Boer 1999). Snails were also found to avoid S. vulgaris early in season, when nitrogen concentrations were higher than later in season (Hägele and Rahier 2001). The authors suggest that this seasonal acceptance of $S$. vulgaris as food is due to the lower PA concentrations later in season. However, recently high nitrogen levels themselves have been reported to be detrimental for herbivore performance (Zehnder and Hunter 2009).

\section{Verifying predictions: the effects of nutrient manipulations in Senecio on herbivores and pathogens}

There were very few studies of the effects of nutrient manipulations in Senecio on herbivores and pathogens (Table 2). The literature on the response of pathogens to Senecio with varying nutrient supplies is limited to a few studies with the rust Puccinia. Puccinia has been applied as biocontrol against Senecio vulgaris (Frantzen et al. 2002). For this pathogen, nutrient status of the plant is crucial, since phosphorus-limited plants are not infected by Puccinia (West 1995). Similarly, Paul and Ayres (1986) found that infection with rust caused growth reductions only at moderate to high nutrient conditions. The fungus itself does not seem to benefit from nutrients, since leaf area occupied was similar between nutrient treatments (Paul et al. 1990). It is not clear whether decreased PA concentrations do play a role in the positive effect of nutrients on 
Table 2 Effect of nutrient supply on herbivores and pathogens of Senecio plants

\begin{tabular}{llll}
\hline Reference & Senecio species & Fertilizer & Herbivore/pathogen $^{\text {Effect }}$ \\
\hline Paul and Ayres 1986 & vulgaris & NPK & Puccinia lagenophorae \\
Paul et al. 1990 & vulgaris & NPK & Puccinia lagenophorae \\
Wilcox and Crawley 1988 & jacobaea & N & Tyria jacobaeae \\
Müller et al. 2005 & jacobaea & NPK & Aphis jacobaeae \\
Bossdorf et al. 2009 & inaequidens & NPK & Aulacorthum solani \\
\hline
\end{tabular}

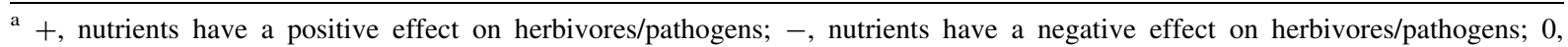
nutrients have no effect on herbivores/pathogens; $n a$, not available

Puccinia infection. In other species that do not contain PAs, Puccinia also developed faster on plants in nutrient-rich habitats (van den Berg et al. 2008).

The earliest study on the effect of fertilization on a herbivore of Senecio was done with the cinnabar moth, which is a specialist insect, on S. jacobaea (Wilcox and Crawley 1988). Fertilization consisted of adding ammonium sulphate once early in season. Since larval performance of the cinnabar moth does not correlated with total PA concentration or the diversity of PAs (Macel et al. 2002), but rather depend on nitrogen content, a positive effect of the nitrogen fertilization could be expected. However, the fertilization might not have been sufficient, since there was no significant difference in total $\mathrm{N}$ concentration or PA content. Unfortunately, the reliability of the PA analysis in this study is questionable, since other compounds besides alkaloids may have been measured (Wilcox and Crawley 1988). Given the equal nitrogen and PA content after fertilization, no effect from the fertilizer treatment on the specialist herbivore was expected. Surprisingly, larvae of the cinnabar moth had lower fresh weight when feeding on $\mathrm{N}$-fertilized S. jacobaea leaves compared to larvae reared on leaves from unfertilized control plants (Wilcox and Crawley 1988). Yet, egg batches were larger on fertilized plants, showing that ovipositing cinnabar moths do not select the most suitable host for their offspring. The authors suggest that changes in amino acids might be responsible for the oviposition behavior and larval growth. Nowadays techniques are available not only to look at PAs into detail, but also include other compounds (Leiss et al. 2009).

In an experiment with another specialist herbivore, Aphis jacobaeae, NPK fertilizer was applied weekly to $S$. jacobaea plants at two sites (Müller et al. 2005). Plant biomass was increased at one site, but no data on nitrogen or PAs were available (Müller et al. 2005).
Lower PA concentrations might be expected based on the reviewed papers (Table 1), but this probably would not affect the specialist $A$. jacobaeae. In fact, at both sites no effect of fertilization on $A$. jacobaeae was found; predators were the main determinant of aphid colony growth (Müller et al. 2005).

The third study is rather different from those discussed above. Twenty-three populations of $S$. inaequidens were grown at two levels of nutrient availability (Bossdorf et al. 2008). Although for this plant species the effect of fertilizer on PA levels has never been reported, a dilution of PAs could be expected since the fertilizer increased shoot biomass more than root biomass (Bossdorf et al. 2008). The consequences of NPK fertilization for herbivory were tested with a generalist aphid, Aulacorthum solani. Both fertilizer and aphids had significant impact on plant biomass, while no interaction was found for the effects of fertilizer and aphids on plant parameters. Aphid numbers are not reported in this paper, but the absence of an interaction between aphids and fertilizer implies that aphids were not affected by fertilization. If the aphids benefited from fertilizer application to their host, the damage to the plants would have increased and hence an interaction between fertilizer and aphids would be expected.

The limited evidence so far shows only little or no effects of fertilization on herbivory and pathogens.

\section{Conclusions and perspectives}

Summarizing, nutrients decrease PA concentrations in S. jacobaea, S. vulgaris and S. aquaticus plants. Nutrient addition consisted mostly of NPK or N alone. It is necessary to study the effect of each element of nutrients separately and combined in order to gain more insight in the effect of nutrients on PA 
content in Senecio plants. The most obvious mechanism behind this decrease in PAs is dilution due to biomass increase. For verification of this, studies should not only report concentration of one plant part, but do the whole PA budget: concentrations and biomass of all plant parts in order to calculate total production. Dilution is not the only factor causing shifts in PA concentrations, since individual PAs were found to vary in their response to fertilization. The next step is a closer look at individual PAs by applying techniques such as GC-MS or NMR to reveal how nutritional status of plants regulates metabolites.

Pathogen infection did respond positively to improved nutrient status of the plants, and thus the upside of fertilization is that plants are more susceptible to pathogens. It remains to be seen whether this will improve biocontrol of Senecio weeds.

In contrast, insect herbivory was not or negatively affected by nutrients, instead of the positive effect that was expected based on the assumption that nutrients would decrease PA concentration. However, only very few studies looked at the effect of fertilizer on herbivores and pathogens and in those studies the fertilization treatments were not always successful, based on plant growth. In those treatments were fertilizer treatments did affect PA concentration, other changes in plant quality may override the PA effect and this should be tested in the future by using a more holistic approach, including primary metabolites and other secondary metabolites besides PAs.

Acknowledgments The constructive comments of two anonymous referees are greatly appreciated. The author thanks all members of the department of Plant Ecology at the University of Leiden for the pleasant critical atmosphere. This is publication 4805 of the Netherlands Institute of Ecology (NIOO-KNAW).

Open Access This article is distributed under the terms of the Creative Commons Attribution Noncommercial License which permits any noncommercial use, distribution, and reproduction in any medium, provided the original author(s) and source are credited.

\section{References}

Berenbaum MR (1995) Turnabout is fair play: secondary roles for primary compounds. J Chem Ecol 21:925-940

Bossdorf O, Lipowsky A, Prati D (2008) Selection of preadapted populations allowed Senecio inaequidens to invade Central Europe. Divers Distrib 14:676-685
Brown MS, Molyneux RJ (1996) Effects of water and mineral nutrient deficiencies on pyrrolizidine alkaloid content of Senecio vulgaris flowers. J Sci Food Agr 70:209-211

de Boer NJ (1999) Pyrrolizidine alkaloid distribution in Senecio jacobaea rosettes minimises losses to generalist feeding. Entomol Exp Appl 91:169-173

Frantzen J, Rossi F, Müller-Schärer H (2002) Integration of biological control of common grounsel (Senecio vulgaris) and chemical control. Weed Sci 50:787-793

Frischknecht PM, Schuhmacher K, Müller-Schärer H et al (2001) Phenotypic plasticity of Senecio vulgaris from contrasting habitat types: growth and pyrrolizidine alkaloid formation. J Chem Ecol 27:343-358

Hägele BF, Rahier M (2001) Determinants of seasonal feeding of the generalist snail Arianta arbustorum at six sites dominated by Senecioneae. Oecologia 128:228-236

Hartley SE, Jones CG, Couper GC et al (2000) Biosynthesis of plant phenolic compounds in elevated atmospheric $\mathrm{CO} 2$. Global Change Biol 6:497-506

Hartmann T, Zimmer M (1986) Organ-specific distribution and accumulation of pyrrolizidine alkaloids during the lifehistory of 2 annual Senecio species. J Plant Physiol 122:67-80

Hartmann T, Ehmke A, Eilert U et al (1989) Sites of synthesis, translocation and accumulation of pyrrolizidine alkaloid N-oxides in Senecio vulgaris L. Planta 177:98-107

Hawkes CV, Douglas AE, Fitter AH (2010) Origin, local experience, and the impact of biotic interactions on native and introduced Senecio species. Biol Invasions 12: 113-124

Höft M, Verpoorte R, Beck E (1996) Growth and alkaloid contents in leaves of Tabernaemontana pachysiphon Stapf (Apocynaceae) as influenced by light intensity, water and nutrient supply. Oecologia 107:160-169

Hol WHG, van Veen JA (2002) Pyrrolizidine alkaloids from Senecio jacobaea affect fungal growth. J Chem Ecol 28:1763-1772

Hol WHG, Vrieling K, van Veen JA (2003) Nutrients decrease pyrrolizidine alkaloid concentrations in Senecio jacobaea. New Phytol 158:175-181

Joosten L, Mulder PPJ, Klinkhamer PGL et al (2009) Soilborne microorganisms and soil-type affect pyrrolizidine alkaloids in Jacobaea vulgaris. Plant Soil 325:133-143

Kandeler E, Tscherko D, Bardgett RD et al (1998) The response of soil microorganisms and roots to elevated $\mathrm{CO} 2$ and temperature in a terrestrial model ecosystem. Plant Soil 202:251-262

Kirk H, Vrieling K, van der Meijden E et al (2009) Plant hybridization and secondary metabolite expression: a case study of pyrrolizidine alkaloids in the genus Senecio. In: Kirk H (2009) Natural hybridization between Senecio jacobae and Senecio aquaticus: ecological outcomes and evolutionary consequences. Dissertation, Leiden University

Koricheva J (1999) Interpreting phenotypic variation in plant allelochemistry: problems with the use of concentrations. Oecologia 119:467-473

Kowalchuk GA, Hol WHG, van Veen JA (2006) Rhizosphere fungal communities are influenced by Senecio jacobaea pyrrolizidine alkaloid content and composition. Soil Biol Biochem 38:2852-2859 
Leishman MR, Sanbrooke KJ, Woodfin RM (1999) The effects of elevated $\mathrm{CO} 2$ and light environment on growth and reproductive performance of four annual species. New Phytol 144:455-462

Leiss KA, Müller-Schärer H (2001) Adaptation of Senecio vulgaris (Asteraceae) to ruderal and agricultural habitats. Am J Bot 88:1593-1599

Leiss KA, Choi YH, Abdel-Farid IB et al (2009) NMR Metabolomics of Thrips (Frankliniella occidentalis) resistance in Senecio hybrids. J Chem Ecol 35:219-229

Lopez-Garcia MC, Maillet J (2005) Biological characteristics of an invasive south African species. Biol Invasions 7:181-194

Macel M (2010) Attract and deter: a dual role for pyrrolizidine alkaloids in plant-insect interactions. Phytochem Rev (in press). doi: 10.1007/s11101-010-9181-1

Macel M, Klinkhamer PGL (2010) Chemotype of Senecio jacobaea affects damage by pathogens and insect herbivores in the field. Evol Ecol 24:237-250

Macel M, Klinkhamer PGL, Vrieling K et al (2002) Diversity of pyrrolizidine alkaloids in Senecio species does not affect the specialist herbivore Tyria jacobaeae. Oecologia 133:541-550

Mattocks R (1986) Chemistry and toxicology of pyrrolizidine alkaloids. Academic Press, London, pp 42-45

Müller CB, Fellowes MDE, Godfray HCJ (2005) Relative importance of fertiliser addition to plants and exclusion of predators for aphid growth in the field. Oecologia 143:419-427

Palumbo MJ, Putz FE, Talcott ST (2007) Nitrogen fertilizer and gender effects on the secondary metabolism of yaupon, a caffeine-containing North American holly. Oecologia 151:1-9

Paul ND, Ayres PG (1986) The effects of infection by rust (Puccinia lagenophorae Cooke) on the growth of grounsel (Senecio vulgaris L.) cultivated under a range of nutrient concentrations. Ann Bot 58:321-331

Paul ND, Laxmi KA, Ayres PG (1990) Responses of rust (Puccinia lagenophorae) to nutrient supply in grounsel (Senecio vulgaris) and effects of infection on host nutrient relations. New Phytol 115:99-106

Poorter H, Nagel O (2000) The role of biomass allocation in the growth response of plants to different levels of light, $\mathrm{CO} 2$, nutrients and water: a quantitative review. Aust J Plant Physiol 27:595-607

Poutaraud A, Girardin P (2005) Influence of chemical characteristics of soil on mineral and alkaloid seed contents of Colchicum autumnale. Environ Exp Bot 54:101-108

Prins AH, Vrieling K, Klinkhamer PGL et al (1990) Flowering behavior of Senecio jacobaea-effects of nutrient availability and size-dependent vernalization. Oikos 59: 248-252

Qasem JR, Hill TA (1995) Growth, development and nutrient accumulation in Senecio vulgaris L. and Chenopodium album L. Weed Res 35:187-196

Radford IJ, Cousens RD (2000) Invasiveness and comparative life-history traits of exotic and indigenous Senecio species in Australia. Oecologia 125:531-542

Rossi G, Parolo G, Ulain T (2009) Human trampling as a threat factor for the conservation of peripheral plant populations. Plant Biosyst 143:104-113
Ryals JA, Neuenschwander UK, Willits MG et al (1996) Systemic acquired resistance. Plant Cell 8:1809-1819

Schaffner U, Vrieling K, van der Meijden E (2003) Pyrrolizidine alkaloid content in Senecio: ontogeny and developmental constraints. Chemoecol 13:39-46

Sindel BM, Michael PW (1992) Growth and competitiveness of Senecio madagascariensis poir (fireweed) in relation to fertilizer use and increases in soil fertility. Weed Res 32:399-406

Smith LW, Culvenor CCJ (1981) Plant sources of hepatoxic pyrrolizidine alkaloids. J Nat Prod 44:129-152

Soldaat LL, Vrieling K (1992) The influence of nutritional and genetic factors on larval performance of the cinnabar moth, Tyria jacobaeae. Entomol Exp Appl 62:29-36

Sreevalli Y, Kulkarni RN, Baskaran K et al (2004) Increasing the content of leaf and root alkaloids of high alkaloid content mutants of periwinkle through nitrogen fertilization. Ind Crop Prod 19:191-195

Suter M, Luscher A (2008) Occurrence of Senecio aquaticus in relation to grassland management. Appl Veg Sci 11:317-324

Suter M, Siegrist-Maag S, Connolly J et al (2007) Can the occurrence of Senecio jacobaea be influenced by management practice? Weed Res 47:262-269

van Dam NM, De Jong TJ, Iwasa Y et al (1996) Optimal distribution of defences: are plants smart investors? Funct Ecol 10:128-136

van den Berg F, van den Bosch F, Powers SJ et al (2008) Apical leaf necrosis as a defence mechanism against pathogen attack: effects of high nutrient availability on onset and rate of necrosis. Plant Pathol 57:1009-1016

van der Meijden E, van Bemmelen M, Kooi R et al (1984) Nutritional quality and chemical defense in the ragwortcinnabar moth interaction. J Anim Ecol 53:443-453

van der Meijden E, van Zoelen AM, Soldaat LL (1989) Oviposition by the cinnabar moth, Tyria jacobaeae, in relation to nitrogen, sugars and alkaloids of ragwort, Senecio jacobaea. Oikos 54:337-344

Vrieling K, van Wijk CAM (1994) Cost assessment of the production of pyrrolizidine alkaloids in ragwort (Senecio jacobaea L.). Oecologia 97:541-546

Vrieling K, de Vos H, van Wijk CAM (1993) Genetic analysis of the concentration of pyrrolizidine alkaloids in Senecio jacobaea. Phytochem 32:1141-1144

Vrieling K, de Jong TJ, Klinkhamer PGL et al (1996) Testing tradeoffs among growth, regrowth and anti-herbivore defences in Senecio jacobaea. Entomol Exp Appl 80:189-192

West HM (1995) Soil phosphate status modifies response of mycorrhizal and non-mycorrhizal Senecio vulgaris L. to infection by the rust Puccinia lagenophorae Cooke. New Phytol 129:107-116

Wilcox A, Crawley MJ (1988) The effects of host plant defoliation and fertilizer application on larval growth and oviposition behavior in cinnabar moth. Oecologia 76: 283-287

Zehnder CB, Hunter MD (2009) More is not necessarily better: the impact of limiting and excessive nutrients on herbivore population growth rates. Ecol Entomol 34:535-543

Zubek S, Turnau K, Tsimilli-Michael M et al (2009) Response of endangered plant species to inoculation with arbuscular mycorrhizal fungi and soil bacteria. Mycorrhiza 19: 113-123 